\title{
Rancang Bangun Sistem Informasi Recruitment Berbasis Web Bagi Karyawan Baru
}

\author{
Abdul Hamid Arribathi ${ }^{1}$, Lisda Anggraeni ${ }^{2}$, Riska Putri Gestiarie ${ }^{3}$ \\ 1,2,3Program Studi Sistem Informasi Universitas Raharja \\ Email : ${ }^{1}$ abdulhamid@ raharja.info, ${ }^{* 2}$ Lisda.anggraeni@ raharja.info, ${ }^{3}$ riska.putri@ raharja.info
}

\begin{abstract}
Abstrak
Dalam pengolahan data rekrutmen karyawan masih menggunakan sistem manual sehingga perusahaan mengalami beberapa kendala dalam pencarian berkas pelamar. Maka perlu suatu sistem yang dapat menangani rekrutmen karyawan baru yang dapat menunjang kinerja suatu perusahaan. Dalam penelitian ini peneliti menggunakan analisis SWOT, PHP (Hypertext Preprocessor) digunakan untuk bahasa pemrogramannya, sedangkan software yang digunakan untuk database server sistemnya mengguankan MySQL, dan XAMPP. Dengan adanya sistem rekrutmen karyawan ini dapat memudahkan pelamar untuk dapat langsung mengakses file lamaran yang ada di website, serta memudahkan HRD dalam proses pemilihan karyawan baru.
\end{abstract}

Kata Kunci: Sistem, rekrutmen karyawan, Kinerja, Pelamar.

\begin{abstract}
In processing employee recruitment data, it still uses a manual system so that the company experiences several problems in searching for applicant files. So we need a system that can handle the recruitment of new employees that can support the performance of a company. In this study, researchers used SWOT analysis, PHP (Hypertext Preprocessor) was used for the programming language, while the software used for the database server system was MYSQL, and XAMPP. With this employee recruitment system, it can make it easier for applicants to be able to directly access the application files on the website, as well as make it easier for HRD in the process of selecting new employees..
\end{abstract}

Keywords: System, employee recruitment, performance, applicants.

\section{PENDAHULUAN}

Semakin besar perusahaan, maka semakin membutuhkan cara untuk mengelola sumber daya yang ada. Dimana peran teknologi sangat mendukung dalam pengolahan data di suatu perusahaan, dengan adanya internet dapat memenuhi kebutuhan perusahaan jika di bantu dengan fasilitas sistem yang baik. Oleh karena itu penting bagi perusahaan untuk merekrut karyawan agar mendapatkan calon karyawan yang tepat agar tujuan perusahaan dapat tercapai.

Dalam mengembangkan bisnis suatu perusahaan tentunya sangat ditentukan oleh kualitas karyawannya, untuk mendapatkan karyawan berkualitas yang memenuhi kualifikasi yang dipersyaratkan. Proses rekrutmen merupakan langkah awal bagi sebuah perusahaan untuk dapat memperoleh tenaga kerja yang berkualitas.

Dengan merancang sistem informasi rekrutmen berbasis web dimana prosesnya memberikan kemudahan, tidak hanya bagi perusahaan, tetapi juga bagi calon pelamar. Dalam sistem seleksi karyawan semakin memudahkan perusahaan dalam menyebarluaskan informasi. 
Dan calon pelamar juga mendapatkan keuntungan dari sistem ini, seperti mengurangi biaya transportasi untuk menuju lokasi seleksi atau biaya melengkapi dokumen lainnya.

\section{LANDASAN TEORI}

\section{Rekrutmen}

Muslihat (2020:31), berpendapat bahwa rekrutmen adalah suatu proses pencarian sumber daya manusia untuk memenuhi kebutuhan sumber daya manusia dalam organisasi. Rekrutmen dimulai dari proses pencarian pelamar baik dari lingkungan internal maupn eksternal organisasi. Pelamar mengajukan surat lamaran, kemudian aurat lamaran diajukan pelamar seleksi sesuai dengan job specification yang telah ditetapkan.[1]

\section{Karyawan}

Zamzami dkk (2021:52), Karyawan merupakan unsur penting dalam setiap pengendalian internal. Jika perusahaan mempunyai karyawan yang kompeten dan jujur, maka unsur pengendalian internal yang lain dapt dikurangi sampai batas minimum dan perusahaan tetap mampu menghasilkan pertanggungjawaban keuangan yang handal. Pengendalian internal yang baik tidak akan dapat menghasilkan informasi keuangan yang andal jika dilaksanakan oleh karyawan yang tidak kompeten dan jujur.[2]

\section{Kinerja}

Sinaga dkk (2020:13), Kinerja (performance) adalah tingkat pencapaian atau hasil aktual seseorang yang dihitung secara berkala baik secara kualitas maupun kuantitas berdasarkan sasaran, standar dan kriteria yang telah ditentukan sebelumnya sebagai hasil kewenangan dan tanggung jawab sebagai suatu pekerjaan di suatu perusahaan atau organisasi.[3]

\section{Analisa SWOT}

Sari dkk (2020:109 ), Analisis SWOT adalah evalausi menyeluruh atas kekuatan, kelemahan, peluang, dan ancaman yang dimiliki dan dihadapi oleh perusahaan. Jika analisa kekeuatan dan kelemahan adalah analisa terhadap kondisi internal perusahaan, maka peluang dan ancaman merupakan analisis kondisi eksternal perusahaan.[4]

\section{LITERATUR REVIEW}

Beberapa hasil penelitian sebelumnya sejalan dengan penelitian ini, antara lain :

1. Januar dkk (2020)[5] dalam penelitiannya Perancangan Sistem Informasi Rekrutmen Tenaga Kerja Kontrak Berbasis Web, hasil dari penelitian ini membantu para staf SDM terutama dalam hal penyusunan data berkas lamaran, data CV dan juga dokumen pendukung lainnya agar menjadi teratur dan dan tersimpan dengan baik.

2. Handayani dkk (2018)[6] dalam penelitiannya Sistem Pendukung Keputusan Penerimaan Karyawan Dengan Menggunakan Metode Analytical Hierarchy Process (AHP), hasil penelitiannya memudahkan menentukan pelamar mana yang benar-benar berkompeten dan layak menjadi karyawan pada perusahaan tersebut.

3. Astriyani dkk (2019)[7] dalam penelitiannya Perancangan Sistem Informasi Rekrutmen Karyawan Pada Perusahaan Daerah Air Minum (PDAM), hasil dari penelitian ini perlunya sistem informasi manajemen aset berbasis website yang akan mengurangi kendala yang terjadi, sehingga akan memudahkan dalam proses pendataan sehingga pengelolaan data menjadi jelas dan rapi. 


\section{METODE PENELITIAN}

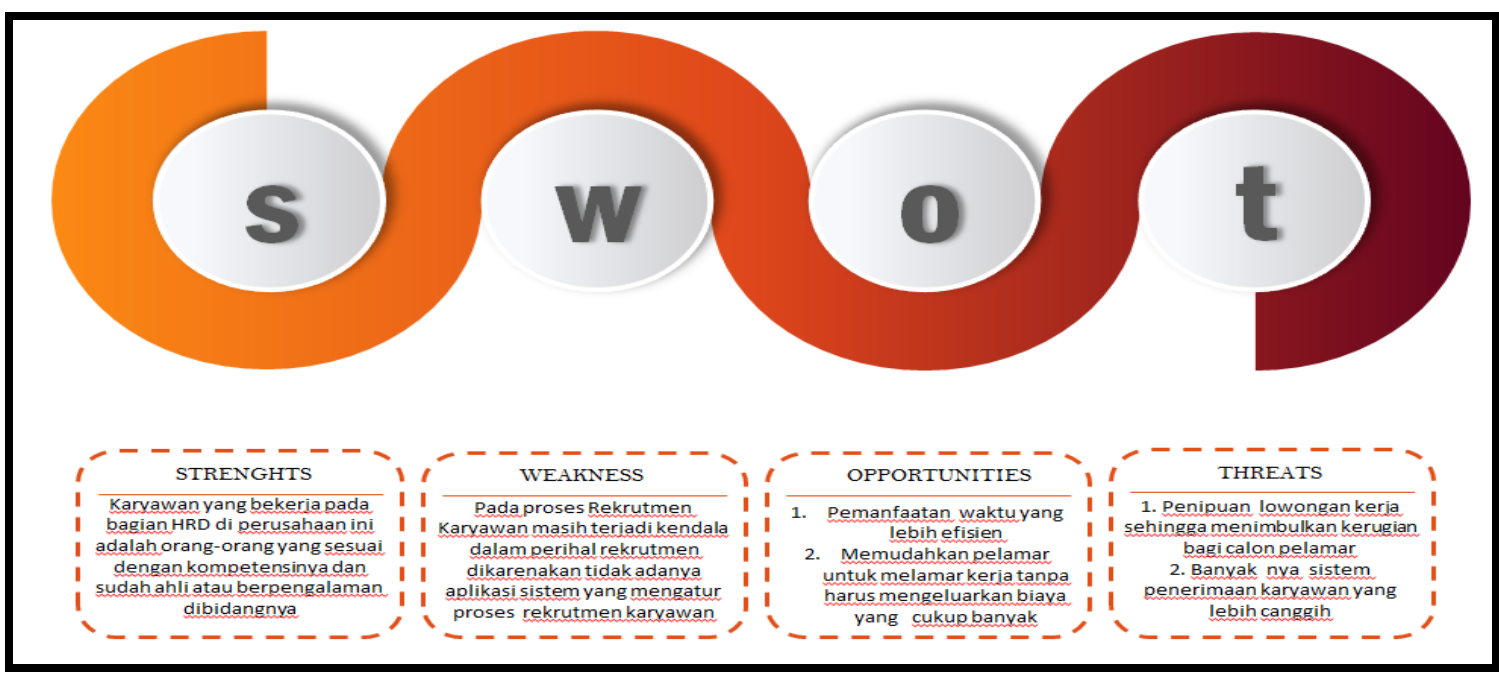

Gambar 1 Metode Analisis SWOT

Metode yang digunakan dalam penelitian ini Berdasarkan gambar yang telah diterangkan diatas mengenai analissis SWOT merupakan teknik perancangan strategi yang berguna untuk melihat kondisi perusahaan baik internal maupun eksternal yang nantinya akan digunakan sebagai indikator untuk mengetahui kekuatan, kelemahan, peluang dan ancaman sehingga dapat membantu perusahaan dalam pengambilan keputusan.

\section{HASIL DAN PEMBAHASAN}

Pada poin ini penulis membahas dalam tahap perancangan sistem yang akan diusulkan untuk memenuhi kebutuhan yang belum ada pada sistem sebelumnya yang digambarkan dalam bentuk class diagram.

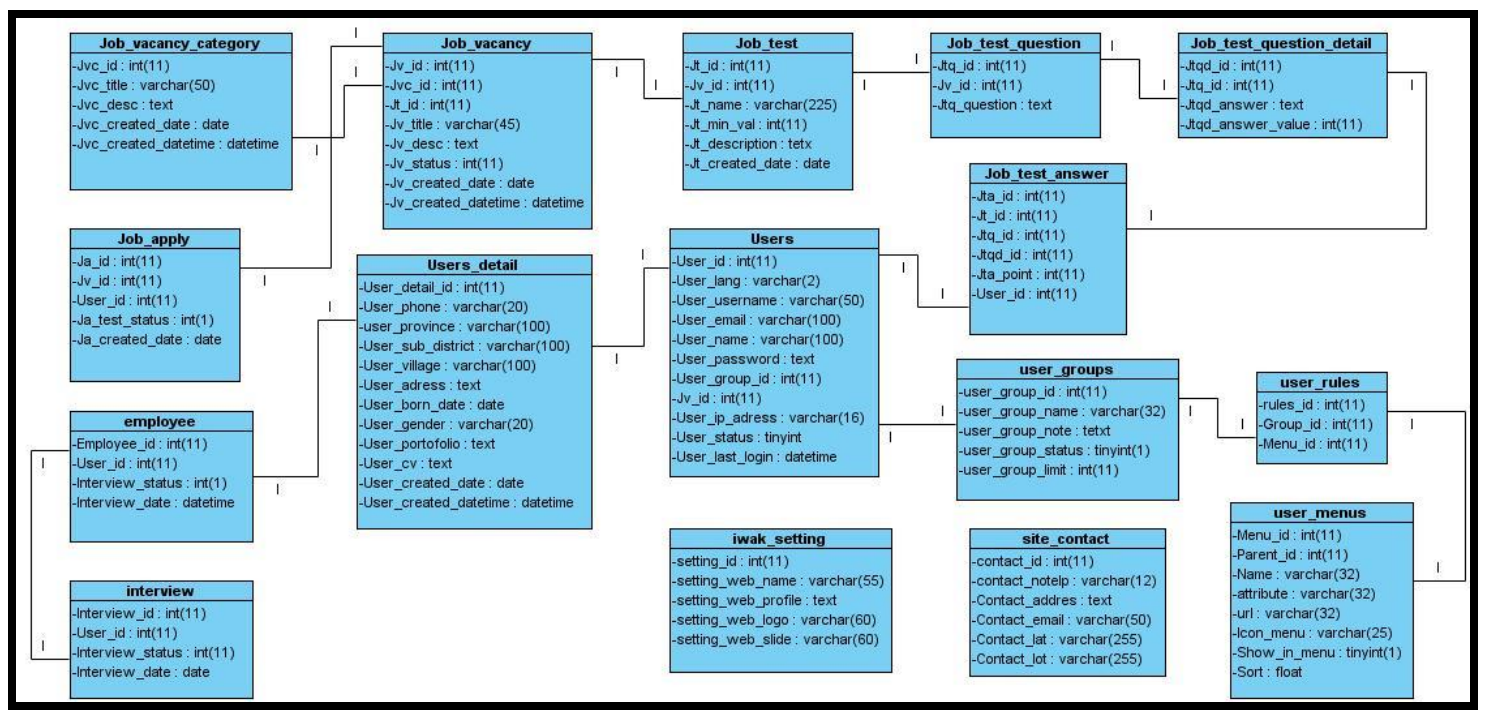

Gambar 2. Class Diagram

Berdasarkan gambar 2. Class diagram sistem yang dibuat terdapat: 16class, himpunan dari objek-objek yang berbagi atribut serta operasi yang sama diantaranya job_vacancy_category, job-vacancy, job_tes, job_tes_question,job_tes_question_detail, 
job_apply, users_detail, users, job_tes_answer, employee, interview, iwak_setting, user_groups, user_rules, site_contact, user_menus. Dan ada 13 association yang mengaitkan satu objek dengan objek lainnya yang memiliki nilai.

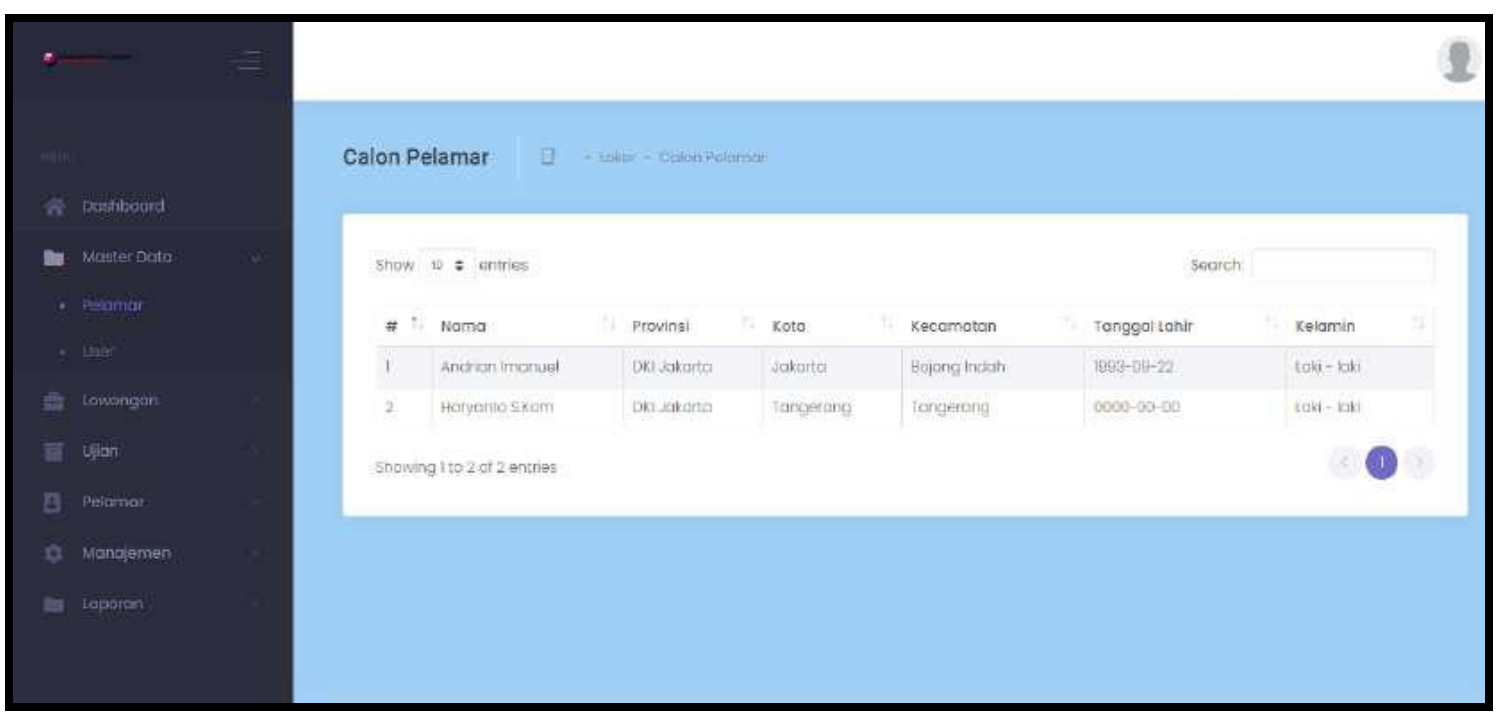

Gambar 3 Tampilan Menu Data Pelamar

Tampilan menu Data Pelamar ini merupakan tampilan nama-nama pelamar yang sudah bisa login pada sistem.

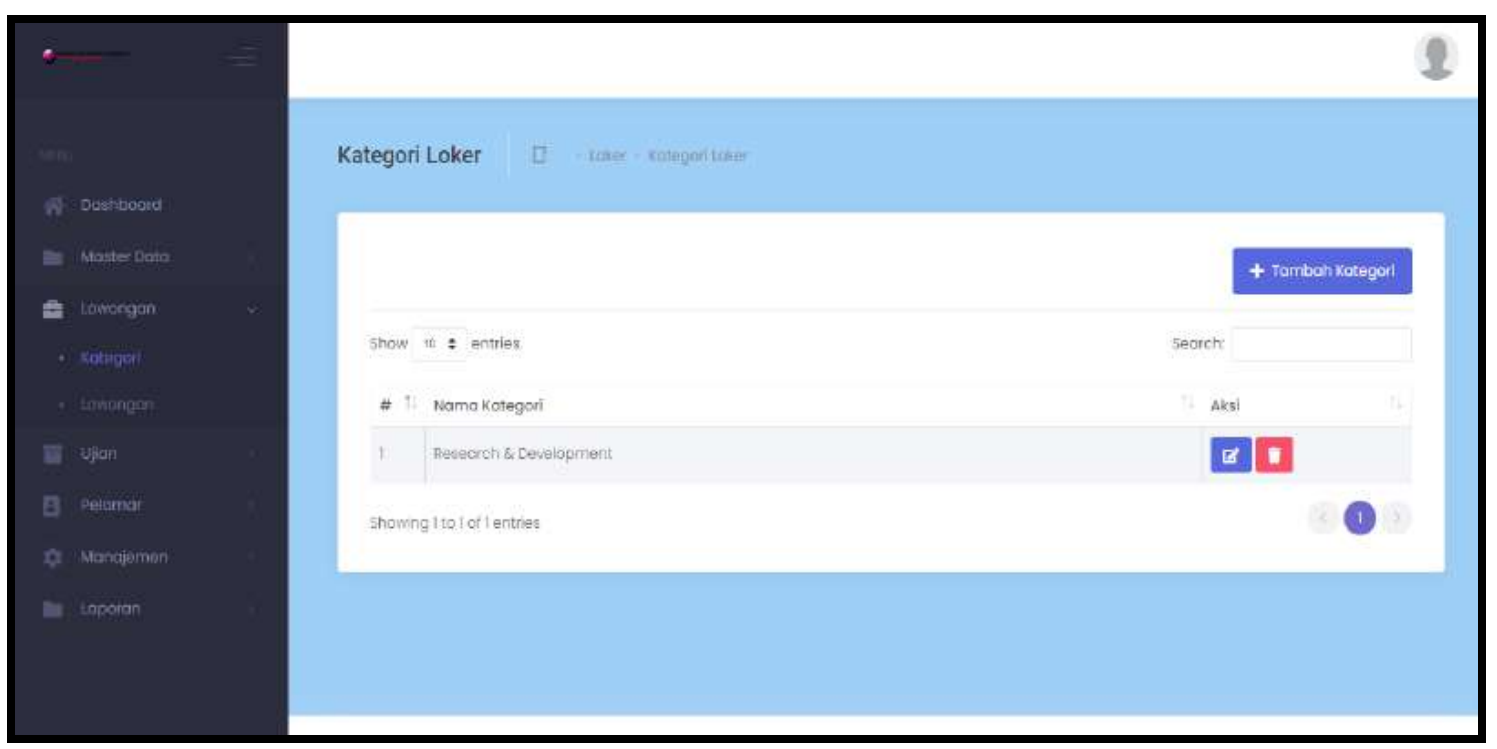

Gambar 4 Menu Lowongan Kategori

Tampilan menu lowongan kategori ini merupakan menu untuk input atau edit kategori lowongan. 


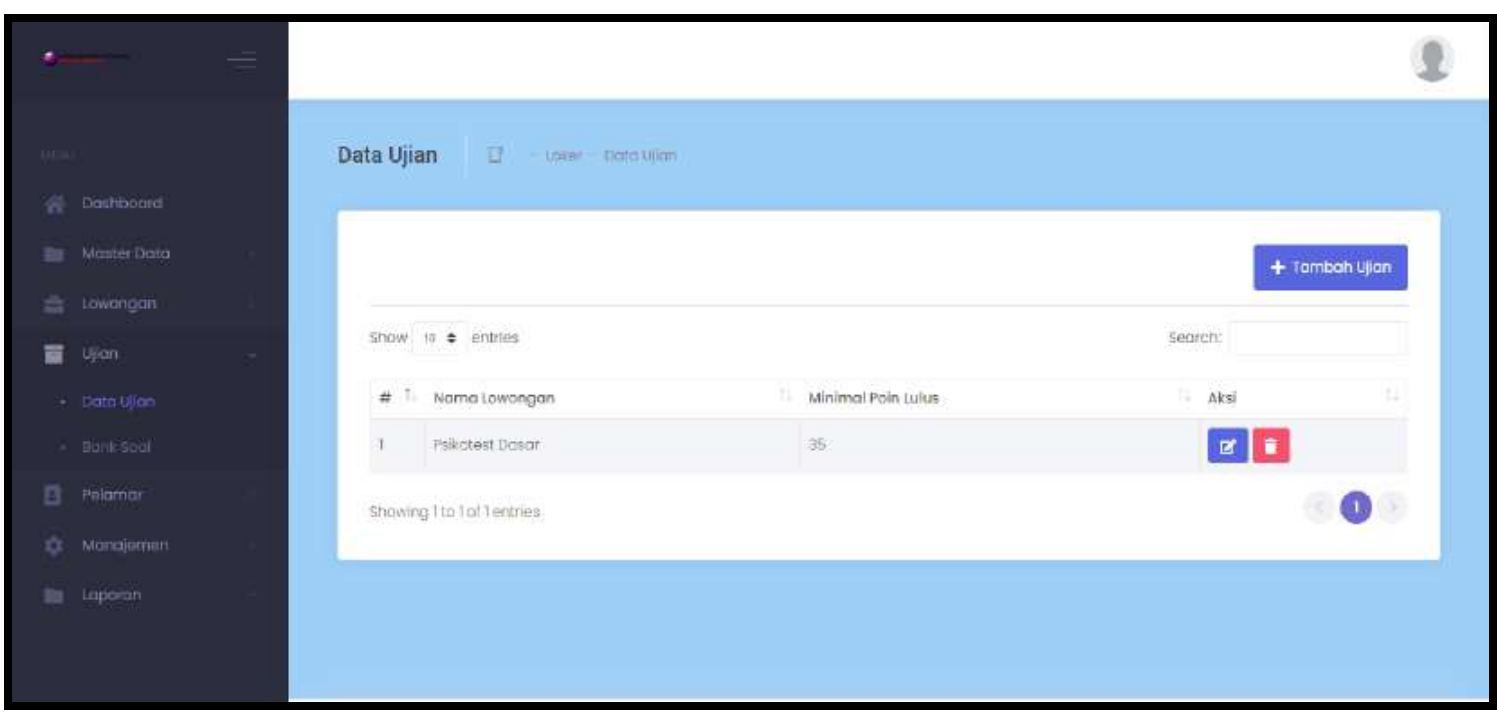

Gambar 5 Tampilan Menu Data Ujian

Tampilan Menu Data Ujian diatas, merupakan menu untuk edit nilai skor minimal point yang lulus.

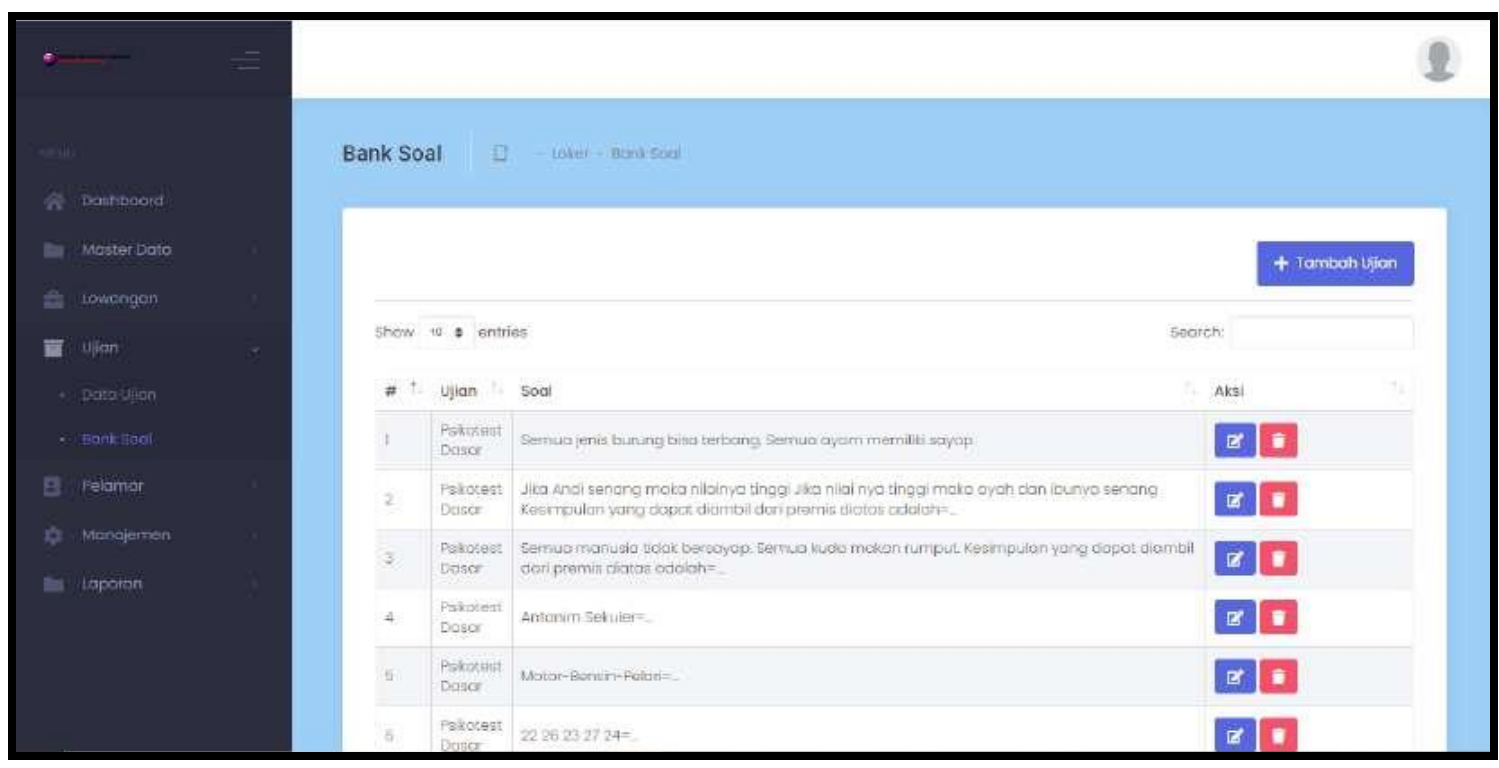

Gambar 6 Tampilan Menu Bank Soal

Tampilan Menu Bank Soal ini berfungsi untuk menginput soal psikotest beserta jawaban, yang nanti nya akan dikerjakan oleh pelamar by sistem. 


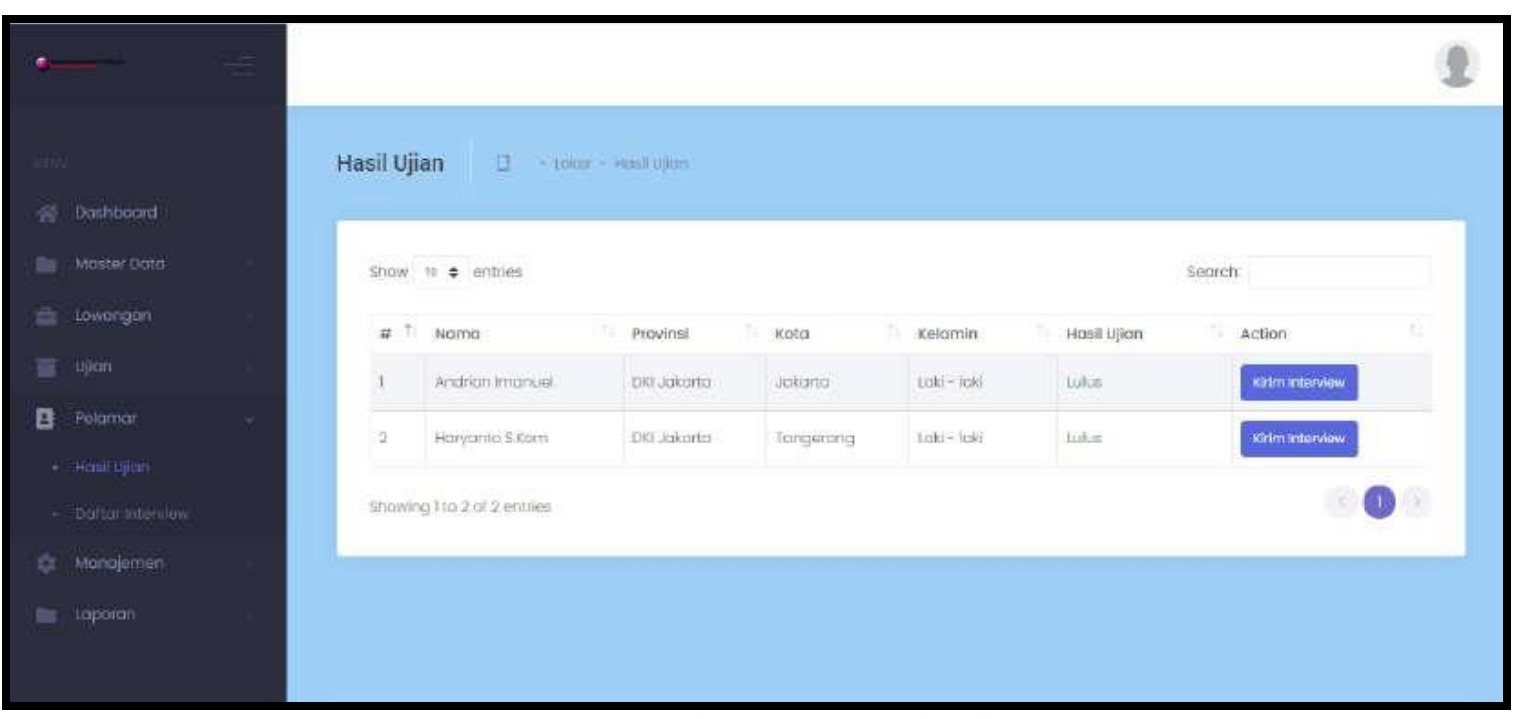

Gambar 7 Tampilan Menu Hasil Ujian

Pada tampilan Menu Hasil Ujian ini terdapat keterangan pelamar yang lulus mengerjakan soal psikotest, yang nanti nya akan dikirim undangan interview by email ke email pelamar tersebut.

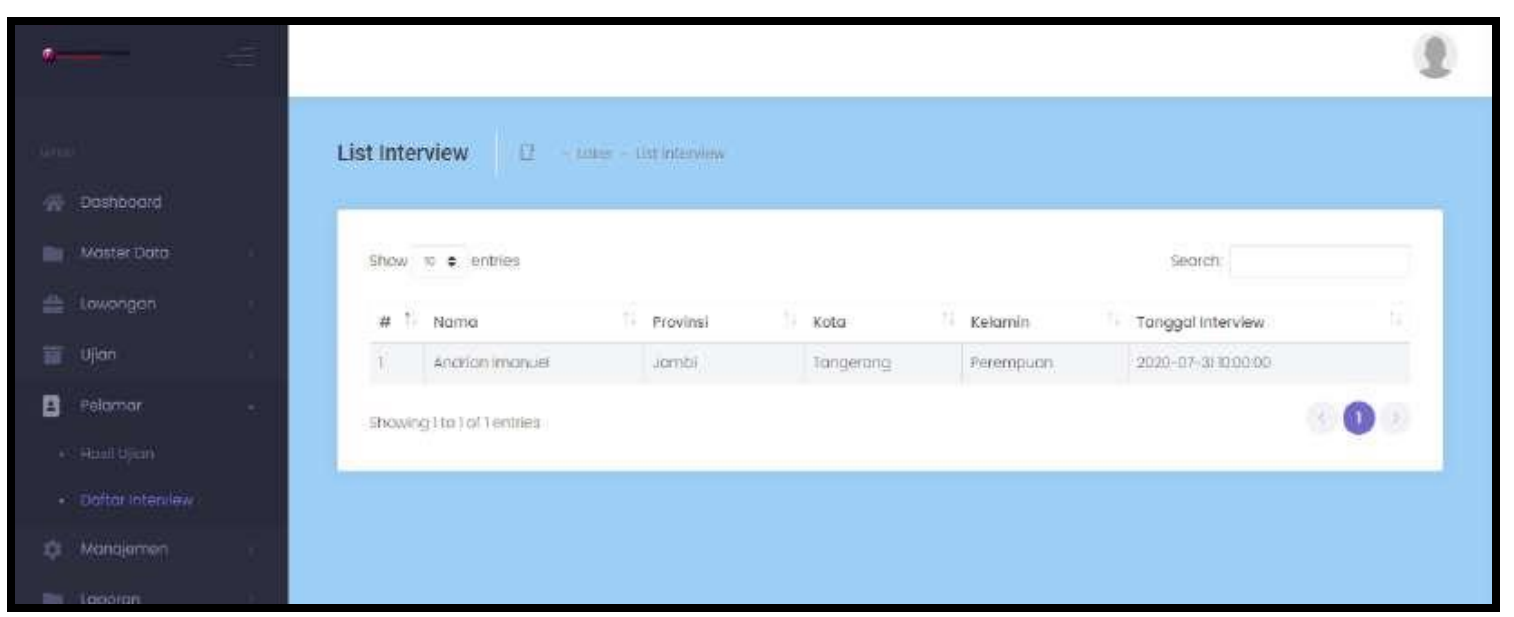

Gambar 8 Tampilan Menu Daftar Interview

Tampilan pada menu Dafar Interview ini, merupakan tampilan data-data pelamar yang sudah dinyatakan lulus psikotest dan dikirim undangan interview oleh pihak HRD. Dimana terdapat tanggal dan jam interview. 


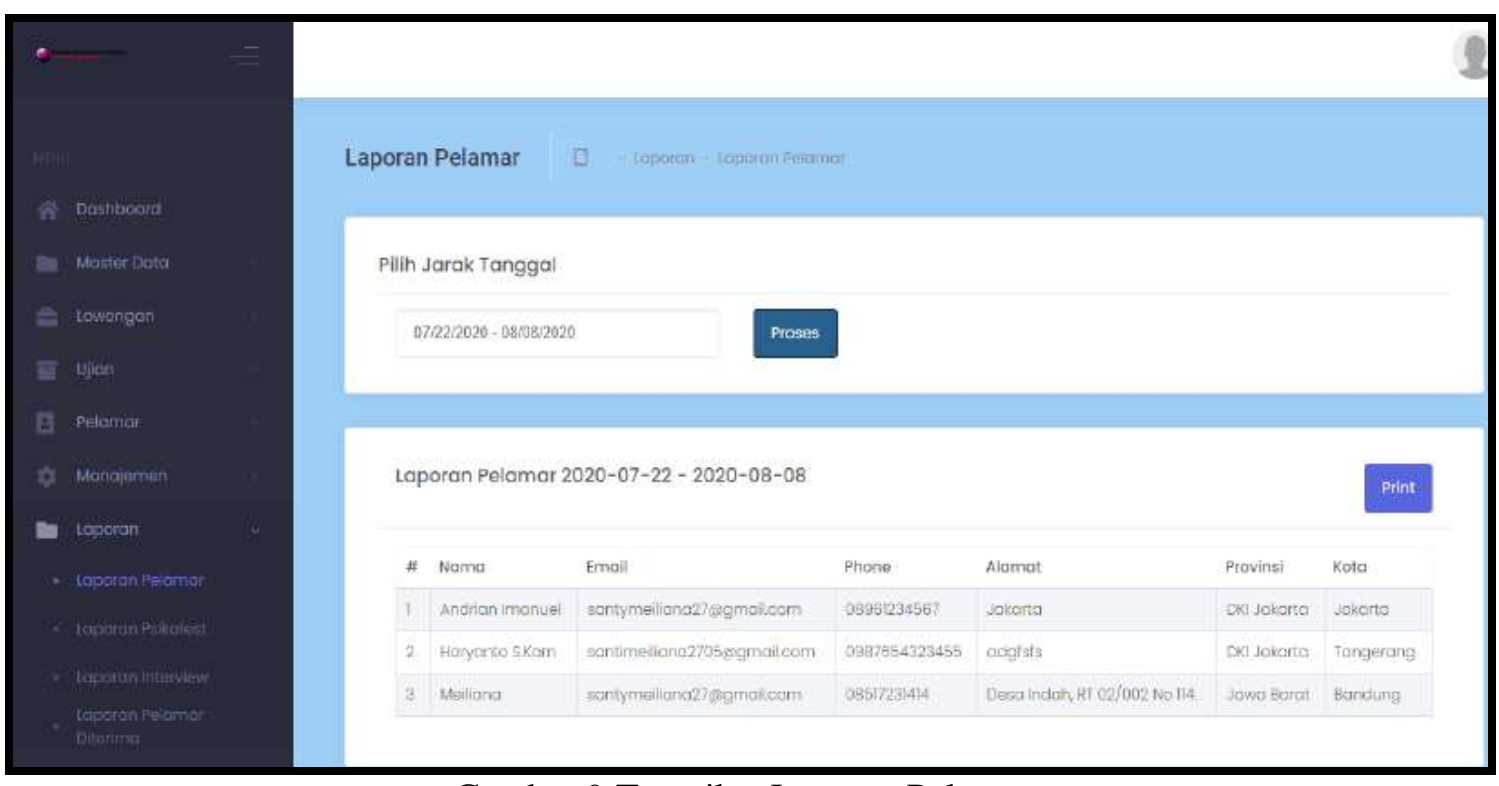

Gambar 9 Tampilan Laporan Pelamar

Pada tampilan Menu Laporan Pelamar diatas, terdapat total keseluruhan pelamar yang mendaftar di sistem rekrutmen.

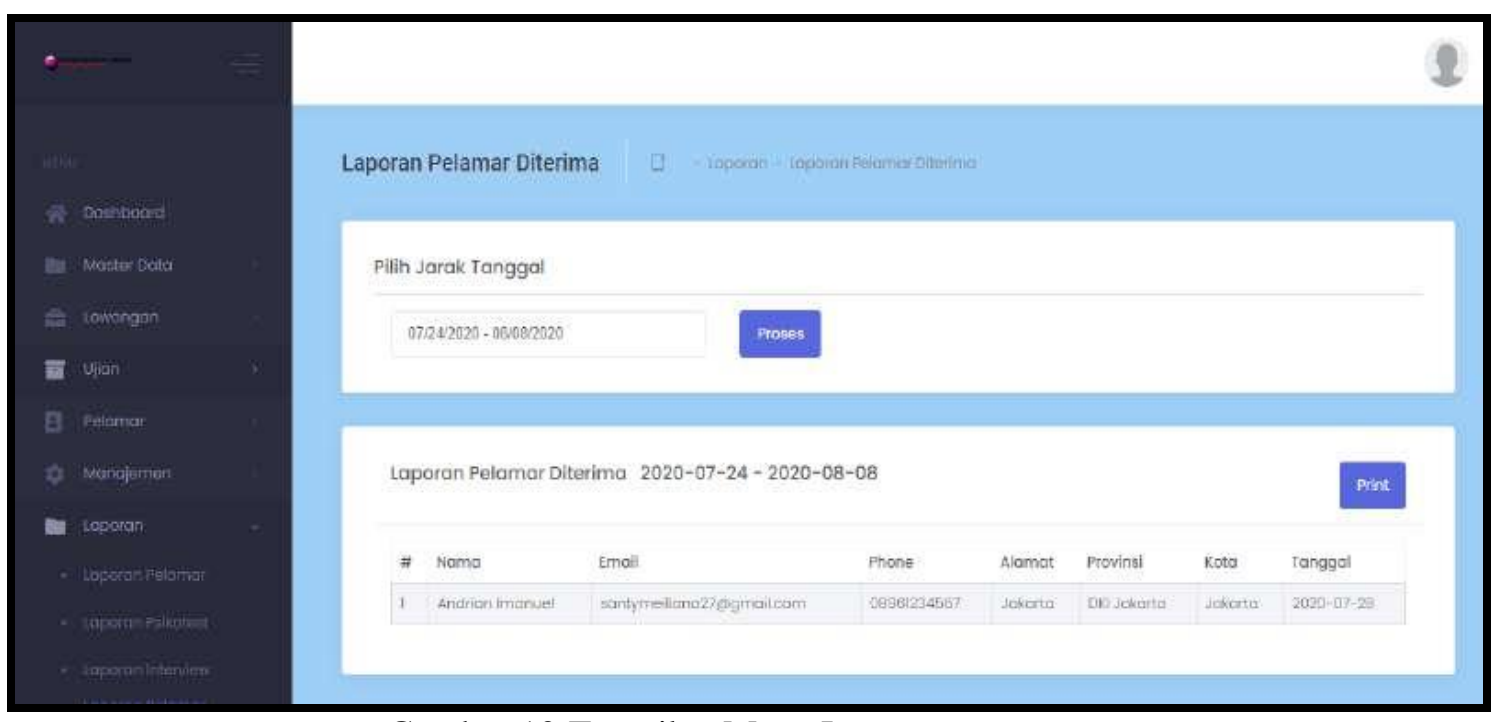

Gambar 10 Tampilan Menu Laporan Interview

Pada tampilan menu tersebut terdapat data pelamar yang benar-benar dinyatakan diterima oleh pihak HRD.

\section{KESIMPULAN}

Dalam pengolahan data rekrutmen karyawan masih menggunakan sistem manual sehingga perusahaan mengalami beberapa kendala dalam pencarian berkas pelamar, diantaranya: masih menggunakan media kertas sehingga banyak dokumen kertas yang hilang, membutuhkan waktu yang lama untuk mencari dokumen. Oleh karena itu, diperlukan sistem yang dapat memudahkan pelamar dan personalia HRD dalam menangani rekrutmen karyawan baru 


\section{SARAN}

Dalam aplikasinya, sistem rekrutmen karyawan baru masih memiliki beberapa kekurangan dan kendala, oleh karena itu peneliti memberikan saran sebagai berikut:

1. Agar aplikasi sistem rekrutmen karyawan yang masih berbasis web dapat dikembangkan menjadi aplikasi mobile dan android.

2. Diperlukan pengembangan dalam tampilan web.

\section{DAFTAR PUSTAKA}

[1] Muslihat, M. 2020. Kepala Madrasah Pada PKKM (Penilaian Kinerja Kepala Madrasah). Yogyakarta : Deepublish (Group Penerbitan CV Budi Utama)

[2] Zamzami, F., Nusa, N, D., \& Faiz, I, A. 2021. Sistem Informasi Akuntansi. Yogyakarta : Gadjah Mada University Press

[3] Sinaga, O, S., dkk. 2020. Manajemen Kinerja Dalam Organisasi. Medan : Yayasan Kita Menulis

[4] Sari, A, P., dkk. 2020. Kewirausahaan dan Bisnis Online. Medan : Yayasan Kita Menulis

[5] Permana, H., Supriyanti, D., \& Kurnia, N. (2020). Perancangan Sistem Informasi Rekrutmen Tenaga Kerja Kontrak Berbasis Web Pada RS.dr.Sitanala Tangerang. Journal Sensi: Strategic of Education in Information System, 6(1), 38-48. Diambil dari : https://ejournal.raharja.ac.id/index.php/sensi/article/view/938

[6] Handayani, R., \& Muzakir, A. (2018). Sistem Pendukung Keputusan Penerimaan Karyawan Dengan Menggunakan Metode Analytical Hierarchy Process (AHP) Studi Kasus : PT. Virtus Venturama. Jurnal Pilar Nusa Mandiri, 14(1), 43-48. Diambil dari : https://ejournal.nusamandiri.ac.id/index.php/pilar/article/view/87

[7] Astriyani, E., Mulyati, M., \& Setiawati, F. (2019). Perancangan Sistem Informasi Rekrutmen Karyawan Pada Perusahaan Daerah Air Minum (Pdam) Tirta Benteng Kota Tangerang. Journal Sensi: Strategic of Education in Information System, 5(2), 214-224. Diambil dari : https://ejournal.raharja.ac.id/index.php/sensi/article/view/136 